CASE REPORT

\title{
Ebstein's malformation with atrial septal defect, right cor triatriatum, and right overt accessory atrioventricular pathway
}

\author{
R-X Wang, X-R Li, D-J Qian
}

Heart 2005;91:e25 (http://www.heartinl.com/cgi/content/full/91/4/e25). doi: 10.1136/hrt.2004.049858

\begin{abstract}
A 31 year old man was admitted to hospital for abrupt syncope. Two dimensional echocardiogram in the apical four chamber view showed Ebstein's malformation. This is the first documented case of Ebstein's malformation with atrial septal defect, right cor triatriatum, and a right overt accessory atrioventricular pathway.
\end{abstract}

\footnotetext{
A
} 31 year old man was admitted to our hospital for abrupt syncope with no history of syncope. The ECG showed sinus rhythm with B type pre-excitation syndrome and atrial fibrillation antegrade conduction by an accessory atrioventricular pathway when the syncope occurred. A two dimensional echocardiogram in the apical four chamber view showed Ebstein's malformation-that is, the septal tricuspid valve was shifted $2.9 \mathrm{~cm}$ to the apex (fig 1A). A fibrous sarcolemma divided the right atrium into two parts (fig 1B), in the middle of which blood flow was detected (fig 1C). An atrial septal defect of about $0.7 \mathrm{~cm}$ was found in the middle of the atrial septum. The blood was found to flow from left to right. Contrast echocardiography with carbon dioxide showed a filling defect in the middle part of right atrial septum, with most of the blood flowing from left to right and less flowing from right to left (fig lD). Refusing to have his anomalies corrected by surgery, the patient accepted radiofrequency catheter ablation treatment and the right overt accessory pathway was successfully blocked.

\section{DISCUSSION}

Ebstein's malformation, also called Ebstein's anomaly, is characterised by a shift of the septal and posterior tricuspid valve towards the right ventricular wall of the apex. The anterior tricuspid valve is positioned normally in most cases. ${ }^{1}$ Ebstein's malformation may have many other kinds of anomalies. Ebstein's malformation with atrial septal defect has been reported to account for $70.6 \%$ of cases. ${ }^{2}$ Other anomalies such as persistent foramen ovale, ventricular septal defect, patent arterial duct, transposition of the great vessels, and cor triatriatum may also be present. Cor triatriatum often appears in the left atrium ${ }^{3}$ and the atrioventricular pathway may lie in the right posterior septum and right free wall. The present patient with Ebstein's malformation had not only an atrial septal defect but also right cor triatriatum and a right overt atrioventricular pathway. To our knowledge, this is the first documented case of Ebstein's malformation with atrial septal defect, right cor triatriatum, and a right overt accessory atrioventricular pathway. The cause of the episode of abrupt syncope was atrial fibrillation antegrade conduction by an accessory atrioventricular pathway. Radiofrequency catheter ablation can be applied to block accessory atrioventricular pathways to prevent sudden cardiac death; however, this patient's anomalies could be corrected with simultaneous operation and pathway resection.

\section{Authors' affiliations}

R-X Wang, X-R Li, D-J Qian, Department of Cardiology, First People's Hospital of Wuxi City and First Affiliated Hospital of Nanjing Medical University in Wuxi, Wuxi, China

Correspondence to: Dr R-X Wang, Department of Cardiology, First People's Hospital of Wuxi City and First Affiliated Hospital of Nanjing Medical University in Wuxi, Wuxi 214002, China; ruxingw@yahoo. com.cn

Accepted 1 November 2004

\section{REFERENCES}

1 Frescura C, Angelini A, Daliento L, et al. Morphological aspects of Ebstein's anomaly in adults. Thorac Cardiovasc Surg 2000;48:203-8.

2 Lazorishinets VV, Glagola MD, Stychinsky AS, et al. Surgical treatment of Wolf-Parkinson-White syndrome during plastic operations in patients with Ebstein's anomaly. Eur J Cardiothorac Surg 2000;18:487-90.

3 From AH, Mazzitello WF, Judd AS, et al. Ebstein's malformation of the tricuspid valve associated with valvular stenosis and cor triatriatum. Chest 1973;64:248-51. 

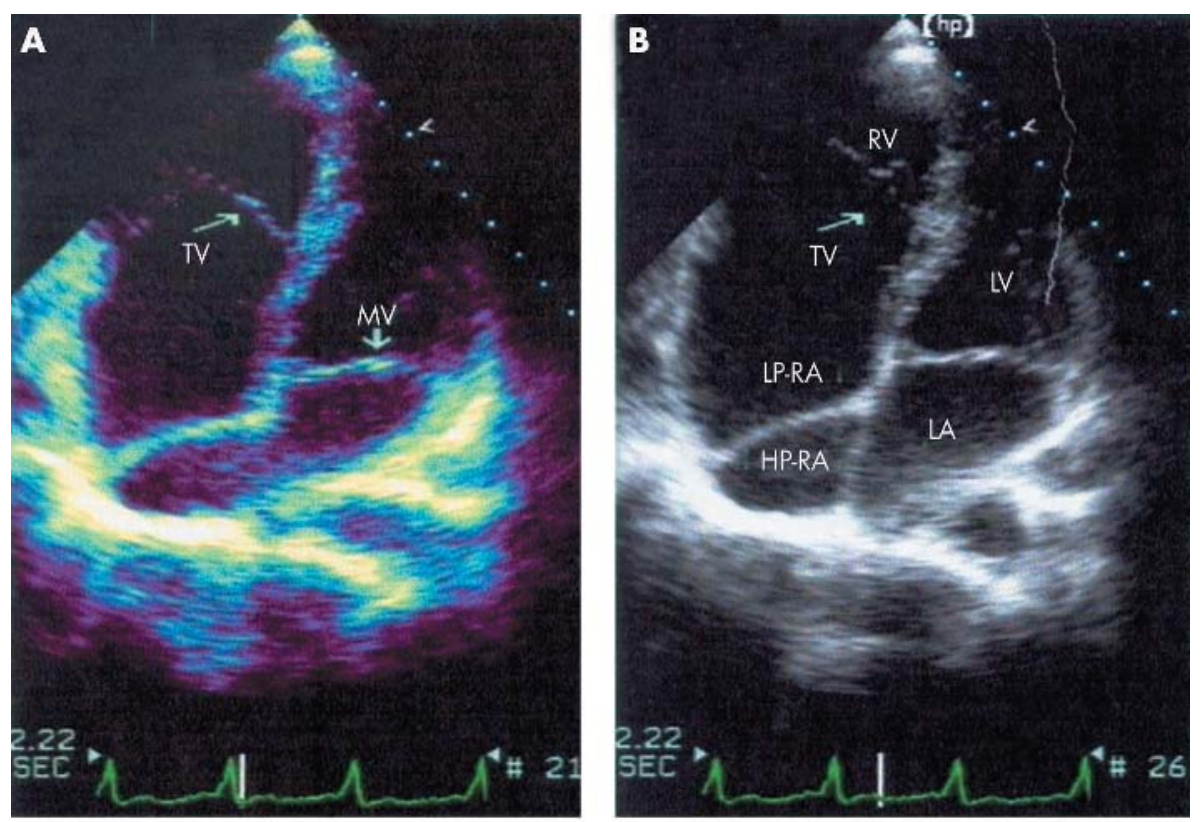

Figure $1 \quad(A-C)$ Two dimensional echocardiograms showing Ebstein's malformation. (D) Contrast

echocardiogram with carbon dioxide. ASD, atrial septal defect; HP-RA, high pressure right atrium; LA, left atrium; LP-RA, low pressure right atrium; LV, left ventricle; $M V$, mitral valve; $R V$, right ventricle. TV, tricuspid valve.
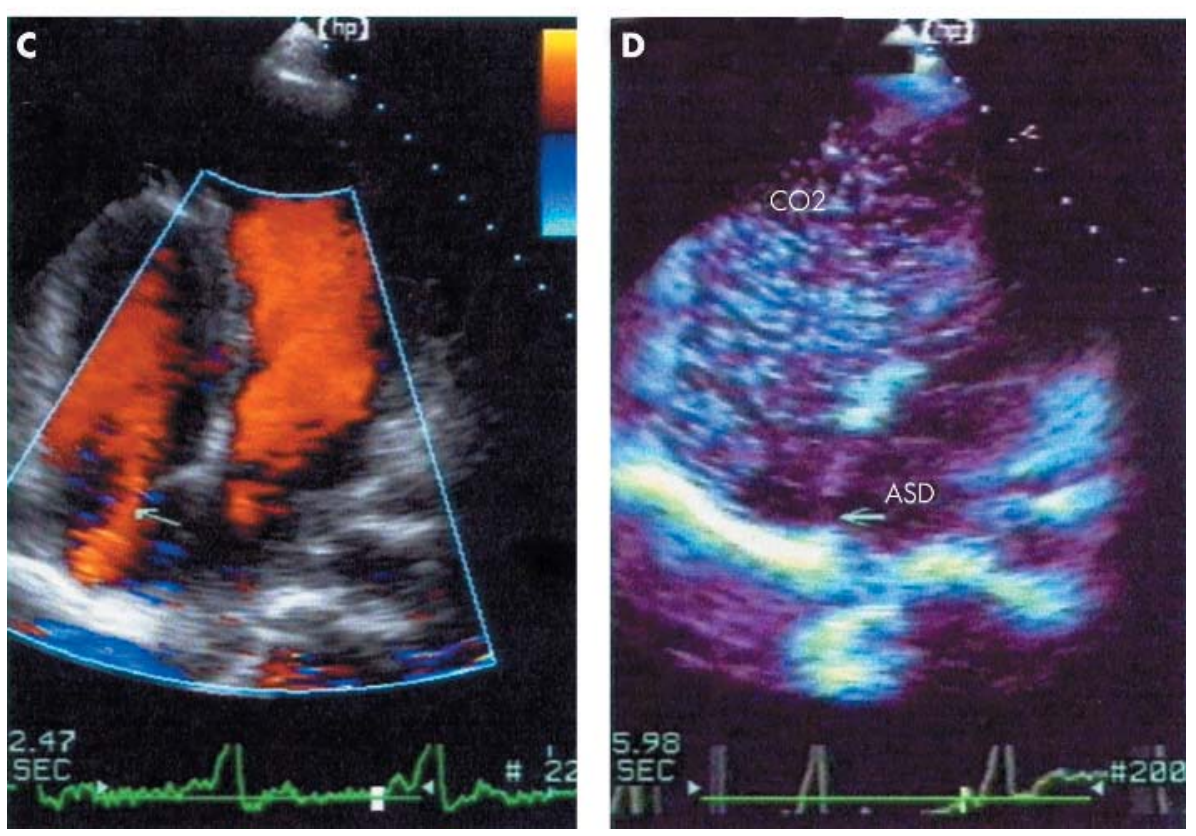